DOI: $10.12731 / 2070-7568-2019-5-50-59$

УДК 338.1

\title{
ПОВЫШЕНИЕ ЭФФЕКТИВНОСТИ \\ УПРАВЛЕНИЯ НЕДВИЖИМОСТЬЮ В УСЛОВИЯХ \\ ЦИФРОВОЙ ЭКОНОМИКИ
}

Макарова E.E.

В статье исследуется прочесс становления информационной системы в современной отечественной экономике, влияние ичифровизации на сферу недвижимости и внедрение в неё новых инструментов и механизмов. Также проведён анализ, выявлены основные проблемы и пути их решения, связанные с этой деятельностью.

Цель работы. Определение проблем в условиях влияния цифрровизации на сферу недвижимости при повышении эффективности управления.

Метод или методология проведения работы: в статье использовались аналитический и статистический методы анализа.

Результаты: сформулированы основные проблемы управления недвижимостью в условиях ичифровизации.

Область применения результатов: полученные результаты цуелесообразно применять экономическими субъектами, осуществляющуими управление недвижимостью в условиях ичифровой экономики.

Ключевые слова: циифровые технологии; недвижимость; изифровая экономика; реинжиниринг; технология блокчейн.

\section{IMPROVING THE EFFICIENCY OF REAL ESTATE MANAGEMENT IN THE DIGITAL ECONOMY}

\section{Makarova E.E.}

The article examines the process of formation of the information system in the modern domestic economy, the impact of digitalization on 
the real estate sector and the introduction of new tools and mechanisms. Also, the analysis and identified the main problems and solutions associated with this activity.

Objective. Definition of problems in the conditions of digitalization influence on the real estate sphere at increase of efficiency of management.

Method or methodology of the work: the article used analytical and statistical methods of analysis.

Results: the main problems of real estate management in the conditions of digitalization are formulated.

Practical implications: the obtained results should be applied by economic entities engaged in real estate management in the digital economy.

Keywords: digital technology; real estate; digital economy; reengineering; technology of the blockchain.

Цифровая трансформация (Digital Transformation) - начало нового этапа эволюции информационной эпохи. В процессе последнего десятилетия произошёл стремительный технологический прорыв, затрагивающий абсолютно все сферы деятельности человека.

Концепция современных новаций в различных сферах жизнедеятельности прямо связана с направлением государственной политики. Главные шаги были предприняты ещё в 2017-2018 гг. после выхода указов Президента Российской Федерации Путина В.В. от 09.05.2017 № 203 [1] и от 07.05.2018 № 204 [2]. В них определены национальные цели и стратегические задачи развития Российской Федерации на временной период до 2030 года.

Немаловажное значение имеет распоряжение Правительства Российской Федерации от 28.07.2017 № 1632-р, в связи с тем, что в документе утверждена программа «Цифровая экономика Российской Федерации». Здесь одной из приоритетных целей ставится создание экосистемы цифровой экономики Российской Федерации, где данные в цифровой форме являются ключевым критерием производства в любой сфере социально-экономической деятельности, к тому же способствующие эффективному взаимодействию всех задействованных субъектов [3]. 
На сегодняшний день данные приобретают статус новых активов, главным образом, из-за их альтернативной ценности, то есть по мере применения информации в новых целях и их задействования при реализации новых идей.

Распространение и развитие телекоммуникационных сетей передачи данных компьютеров, программного обеспечения и других аппаратных средств, принятие нормативных документов, регламентирующих создание и предоставление информации, появление подготовленных профессионалов в сфере информационных технологий, ведение баз данных часто является главным условием для эффективного администрирования рассматриваемой сфере [6, с. 584-589].

Особое место в системе общественных отношений занимает недвижимое имущество, с функционированием которого, связана жизнь и деятельность людей во всех сферах бизнеса.

Рынок недвижимости в настоящее время усиливает свои позиции, так как он позволяет генерировать большие доходы от приобретения и последующей продажи недвижимого имущества [4, с. 73-80].

Одним из таких инструментов, приносящим постоянный доход и сохраняющим капитал, являются вложения в недвижимость. Недвижимости, как любому объекту собственности, свойственна такая характеристика, как инвестиционная привлекательность, то есть коммерческий интерес у инвестора, состоящий в способности недвижимости приносить доход.

Повышенный интерес к инвестициям в недвижимость в условиях рыночной экономики привел к возникновению и активному развитию нового вида инвестиционно-строительной деятельности девелопмента [5, с. 81-86].

Рынок недвижимости, рассматриваемый как один из надежных и доходных способов вложения инвестиций, обеспечивающий сохранение и приумножение стоимости и величины капитала, включает в себя и присущие долгосрочным инвестициям факторы риска. Одним из таких факторов риска для собственников и арендаторов коммерческой недвижимости является сфера налогообложения [7, с. 164-168]. 
Недвижимость - основа национального богатства страны, потому возникает необходимость внедрения цифровизации в данном секторе.

Организациям, работающим на рынке недвижимости, приходится адаптироваться к цифровой трансформации, а значит задумываться о целесообразности, сроках и методах реализации таких инноваций [10].

Цифровая трансформация промышленности - это процесс, отражающий переход промышленного сектора из одного технологического уклада в другой посредством широкомасштабного использования цифровых и информационно-коммуникационных технологий с целью повышения уровня его эффективности и конкурентоспособности [8, с. 145-148].

В основе цифровой трансформации изначально заложена стратегия, а не технологии. Рассмотрены следующие цифровые решения:

- Искусственный интеллект.

К 2030 году планируется, что инновационные решения на основе искусственного интеллекта обеспечат рост ВВП на 11,3\%, и сектор недвижимости не станет исключением. Программные алгоритмы будут активно включаться, и развиваться в более сложных областях. В будущем системы на основе искусственного интеллекта смогут значительно уменьшить долю неверных решений, обусловленных нехваткой данных.

- Дроньl, активно используюшиеся в маркетинге.

Дроны расширяют границы существующих технологий аэрофотосъемки и сенсорного сбора данных и помогают повысить качество решений в различных областях.

- Виртуальная реальность.

Виртуальная реальность - это цифровое конструирование трехмерного изображения или конкретной специально созданной среды. Пользователи могут интуитивно взаимодействовать с моделями виртуальной реальности, максимально приближенной к реальным условиям. Виртуальная реальность позволяет создать эффект погружения и ощутить пространственные данные зданий или вещей.

- Интернет вещзей.

Интернет вещей (IоТ) состоит из экосистемы датчиков, интегрированных компьютеров и интеллектуальных устройств, подклю- 
ченных друг к другу и к облаку, а также используемых для сбора, анализа и оценки данных. Множество областей применения эта технология обрела в системах интеллектуального учета и автоматизации зданий.

На современном этапе данная система позволяет применять различные методы использования анализа и оценки информации в режиме реального времени для того, чтобы сократить затраты и повысить производительность труда.

ІоТ-датчики применяются для измерения энергопотребления зданий, мониторинга их безопасности и оптимизации работ, связанных с содержанием и реконструкцией зданий.

Задействование этой технологии на практике находится на начальном этапе и требует дальнейших доработок. Сейчас затраты на приобретение технологий умного дома или умного офиса, к сожалению, высоки. Однако при дальнейшем распространении технологии станет возможным компенсация затрат за счёт увеличения масштабов.

- 3D-nечать.

3D-печать - технология аддитивного производства, используемая для создания трехмерных объектов по средствам печати при помощи последовательного наложения слоев материала. Помимо изготовления запасных частей (элементов строительных конструкций) в сфере управления объектами недвижимости и инфраструктуры, были разработаны бетонные и цементные принтеры, способствующие строительству зданий.

3D-строительство уже достигло такого уровня, что «напечатанные» бетонные конструкции достигают уровня качества традиционных материалов. Использование технологии трехмерной печати существенно приводит к экономии затрат на время и потребляемые ресурсы.

- Блокчейн.

Блокчейн - это децентрализованный реестр всех операций в одноранговой сети. Используя данную технологию, пользователи могут совершать операции без задействования центра сертификации. Возможные области применения включают денежные переводы, расчеты по операциям, финансирование и многое другое. В 
контексте сектора недвижимости блокчейн может использоваться в ряде областей на всех этапах создания стоимости объекта.

В долгосрочной перспективе блокчейн может поспособствовать увеличению прозрачности рынка и решить вопросы, связанные с отношениями между принципалом и агентом. Первые возможные направления использования данной технологии были намечены только на теоретическом уровне, тогда как практические и готовые к массовому внедрению решения все еще требуют тщательной проработки.

Государственную заинтересованность в изучении вопроса цифровизации показывают события 2019 г. 18 апреля 2019 г. состоялся V Ялтинский международный экономический форум, на котором обсуждалось внедрение инструментов цифровой экономики, международное сотрудничество для развития территорий, инвестирование в высокотехнологичные отрасли, а также повышение качества жизни.

Заместителем Министра экономического развития Российской Федерации - руководителем Росреестра Абрамченко В.В. был представлен доклад на тему «ІТ-платформа «Доверительное управление недвижимостью» как инструмент повышения инвестиционной и туристической привлекательности», который отразил необходимость соответствия уровня и качества электронных сервисов Росреестра потребностям рынка недвижимости [9].

Росреестр и Федеральная кадастровая палата, которая в настоящее время проходит преобразование в сервисную компанию по обслуживанию IT-инфраструктуры в государственном секторе, уже приступили к разработке платформы. Предполагается, что она предоставит гражданам и предпринимателям комплекс возможностей и сервисов при совершении операций с недвижимостью: купле-продаже, аренде, а также при оплате связанных с ними налогов. Планируется, что платформа будет запущена в тестовую эксплуатацию к концу текущего года.

В связи с этим появляется необходимость реинжиниринга существующих сервисов Росреестра. Для этого Росреестр проводит работу по изменению подхода к предоставлению электронных услуг. Для начала будут проводится маркетинговые исследования с участием профессиональных сообществ (кадастровых инженеров, 
застройщиков, нотариусов, представителей банков) с целью выявления направлений повышения качества услуг Росреестра [9].

Благодаря внедрению новых технологических решений пользователи электронных сервисов предоставления сведений из ЕГРН смогут получать актуальные сведения о недвижимости гораздо оперативнее, то есть в течении суток.

В заключении следует отметить, что существует ряд проблем, связанных с повсеместным включением цифровых технологий в различные сферы деятельности:

- несоответствие направлений подготовки в области недвижимости современным требованиям информационного общества;

- низкая доля специалистов, обладающих компетентными знаниями и навыками в сфере цифровой экономики;

- проблема безопасности конфиденциальных данных, возможность взлома и кражи сведений;

- неготовность компаний к изменениям, т.е. многие руководители и сотрудники организаций болезненно относятся к резким и быстрым трансформациям из-за ретроградных взглядов или финансовых затруднений.

Таким образом, государственная власть на всех уровнях должна продемонстрировать, насколько важна цифровая трансформация во всех сферах деятельности населения. Это будет способствовать тому, что общество в полной мере ощутит мотивацию к изучению новых способов работы и сможет изменить свое мышление.

\section{Список литературы}

1. Указ Президента РФ от 09.05.2017 № 203 «О Стратегии развития информационного общества в Российской Федерации на 2017 2030 годы». URL: http://www.consultant.ru/documents/cons_doc_ LAW_216363/ (дата обращения: 03.12.2019 г.).

2. Указ Президента РФ от 07.05.2018 № 204 (ред. от 19.07.2018 г.) «О национальных целях и стратегических задачах развития Российской Федерации на период до 2024 года». URL: http://www.consultant.ru/ documents/cons_doc_LAW_297432/(дата обращения: 03.12.2019 г.). 
3. Распоряжение Правительства РФ от 28.07.2017 № 1632-р об утверждении программы «Цифровая экономика Российской Федерации». URL: http://static.government.ru (дата обращения: 03.12.2019 г.).

4. Макарова Е.Е., Мозолькова А.Е. Эффективность инвестиций в рынок недвижимости // Комплексное социально-экономическое и территориальное развитие Центрального федерального округа сборник научных трудов по материалам Всероссийской научно-практической конференции. 2019. С. 73-80.

5. Макарова Е.Е., Притворов А.А. Девелопмент как основа развития рынка недвижимости // Комплексное социально-экономическое и территориальное развитие Центрального федерального округа сборник научных трудов по материалам Всероссийской научно-практической конференции. 2019. С. 81-86.

6. Проскурина З.Б., Макарова Е.Е. Доверительное управление имущественным комплексом как фактор инновационного развития экономики // Экономика и предпринимательство. 2018. № 8 (97). С. 584-589.

7. Проскурина З.Б. Совершенствование методологии кадастровой оценки объектов недвижимости // Государственное и муниципальное управление. Ученые записки. 2019. №3. С. 164-168.

8. Сыщикова Е.Н., Батова А.В. Цифровая трансформация промышленности и промышленного сотрудничества // Управление инновационно-инвестиционной деятельностью: к 80-летнему юбилею профессора Юрия Петровича Анисимова сборник материалов Всероссийской юбилейной научно-практической конференции. ФГБОУ ВО «Воронежский государственный технический университет». Москва, 2019. С. 145-148.

9. Росреестр. Федеральная служба государственной регистрации и картографии. https://rosreestr.ru/site/press/news/rosreestr-rasskazal-otsifrovizatsii-v-sfere-nedvizhimosti-na-yaltinskom-mezhdunarodnomekonomichesk/ (дата обращения: 05.12.2019 г.).

10. Цифровая трансформация сектора недвижимости. https://www.pwc. $\mathrm{ru} / \mathrm{ru} /$ industries/real-estate/digital-real-estate.html (дата обращения: 08.12.2019 г.). 


\section{References}

1. Decree of the President of the Russian Federation of 09.05.2017 No. 203 «On the strategy for the development of the information society in the Russian Federation for 2017-2030». http://www.consultant.ru/documents/cons_doc_LAW_216363/(date accessed: 03.12.2019).

2. Decree of the President of the Russian Federation of 07.05.2018 No. 204 (ed. of 19.07.2018) «On national goals and strategic objectives of the development of the Russian Federation for the period up to 2024». http://www.consultant. ru/documents/cons_doc_LAW_297432/(date accessed: 03.12.2019).

3. Rasporjazhenie Pravitelstva RF of 28.07.2017 No. 1632-R on approval of the program "Digital economy of the Russian Federation". http:// static.government.ru (date accessed: 03.12.2019).

4. Makarova E.E., Mozolkova A.E. Effektivnost' investitsiy v rynok nedvizhimosti [Efficiency investments in the real estate market]. Kompleksnoe sotsial'no-ekonomicheskoe i territorial'-noe razvitie Tsentral'nogo federal'nogo okruga sbornik nauchnykh trudov po materialam Vserossiyskoy nauchno-prakticheskoy konferentsii [Complex socio-economic and territorial development of the Central Federal district collection of scientific papers on the materials of the all-Russian scientific and practical conference]. 2019, pp. 73-80.

5. Makarova E.E., Pritvorov A.A. Development kak osnova razvitiya rynka nedvizhimosti [Development as a basis for the development of the real estate market]. Kompleksnoe sotsial'no-ekonomicheskoe $i$ territori-al'noe razvitie Tsentral'nogo federal'nogo okruga sbornik nauchnykh trudov po materialam Vserossiyskoy nauchno-prakticheskoy konferentsii [Integrated socio-economic and territorial development of the Central Federal district collection of scientific papers on the materials of the all-Russian scientific and practical conference]. 2019, pp. 81-86.

6. Proskurina Z.B., Makarova E.E. Doveritel'noe upravlenie imushchestvennym kompleksom kak faktor innovatsionnogo razvitiya ekonomiki [Trust management of the property complex as a factor of innovative development of the economy]. Ekonomika i predprinimatel'stvo [Economics and entrepreneurship]. 2018. No. 8 (97), pp. 584-589.

7. Proskurina Z.B. Sovershenstvovanie metodologii kadastrovoy otsenki ob"ektov nedvizhimosti [Enhancement of methodology of cadastral as- 
sessment of real estate objects]. Gosudarstvennoe i munitsipal'noe upravlenie. Uchenye zapiski [State and municipal management. Scientific notes]. 2019. No. 3, pp. 164-168.

8. Syshchikova E.N., Batova A.V. Tsifrovaya transformatsiya promysh-lennosti i promyshlennogo sotrudnichestva [Digital transformation of industry and industrial cooperation]. Upravlenie innovatsionno-investitsionnoy deyatel'nost'yu: $k$ 80-letnemu yubileyu professora Yuriya Pet-rovicha Anisimova sbornik materialov Vserossiyskoy yubileynoy nauchno-prakticheskoy konferentsii [Management of innovation and investment activities: to the 80th anniversary of Professor Yuri Petrovich Anisimov collection of materials of the all-Russian jubilee scientific and practical conference]. Voronezh state technical University. Moscow, 2019, pp. 145-148.

9. Rosreestr. Federal service of state registration and cartography. https://rosreestr.ru/site/press/news/rosreestr-rasskazal-o-tsifrovizatsii-v-sfere-nedvizhimosti-na-yaltinskom-mezhdunarodnom-ekonomichesk/ (date accessed: 05.12.2019).

10. Digital transformation of the real estate sector. https://www.pwc.ru/ru/ industries/real-estate/digital-real-estate.html (date accessed: 08.12.2019.)

\section{ДАННЫЕ ОБ АВТОРЕ}

Макарова Екатерина Евгеньевна, доцент кафедры «Экономики и управления недвижимостью», кандидат экономических наук Российский государственный университет правосудия ул. Новочеремушкинская, 69, г. Москва, 117418, Российская Федерация mak_katusha@mail.ru

\section{DATA ABOUT THE AUTHOR}

Makarova Ekaterina Evgenievna, associate professor «Economy and property management», Candidate of Economic Sciences Russian State University of Justice 69, Novocheremushkinskaya St., Moscow, 117418, Russian Federation mak_katusha@mail.ru SPIN-code: 2838-5305 